International Review of Research in Open and Distributed Learning

Volume 17, Number 1

January - 2016

\title{
Using Positive Visual Stimuli to Lighten The Online Learning Experience through In Class Questioning
}

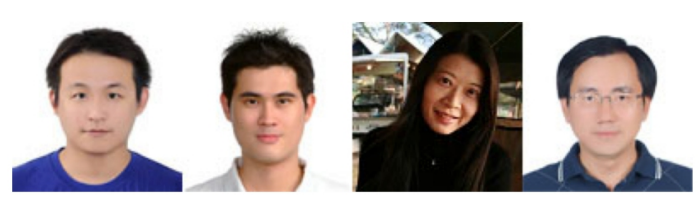

Chia-Hung Lai', Ming-Chi Liu', Chia-Ju Liu', and Yueh-Min Huang,"*

'Department of Engineering Science, National Cheng Kung University, Taiwan, ${ }^{2}$ Graduate Institue of Science Education, National Kaohsiung Normal University, Taiwan, "Corresponding author

\begin{abstract}
Using in-class questions is an efficient instructional strategy to keep abreast of the state of student learning in a class. Some studies have found that discussing in-class questions in synchronous learning is helpful. These studies demonstrated that synchronous questions not only provide students with timely feedback, but also allow teachers to change the pedagogy adaptively. However, some studies have also shown negative results of synchronous questions in that students may resist being questioned because of anxiety. Therefore, this paper proposes an idea of showing students funny images in order to reward them for providing correct answers. The effect of connecting questions with funny image rewards was examined by collecting data on student test scores, on facial expressions and on electroencephalogram (EEG) responses elicited using this strategy. The data on students' facial expressions indicated that being presented with funny images for correct answers consistently helps to arouse positive emotions in participants. Also, the data on the EEG responses showed that the participants receiving the rewarded questions demonstrated a trend toward increasing levels of attention and relaxation. However, the results
\end{abstract}


also revealed that significant improvements in test scores were not apparent regardless of whether or not amusing visual stimuli were used. The findings imply that showing funny images as a stimulus enhances students' affective states in student-teacher interactions during online learning activities.

Keywords: positive visual stimuli, in-class question, online learning, synchronous learning platform, funny image

\section{Introduction}

Although students are familiar with watching video on demand, they lack experience in formal synchronous learning (Cole, 2009; Warden, Stanworth, Ren, \& Warden, 2013). As noted by Warden et al.'s (2013) nine-year action study, creating social interactions within a virtual space that emulates a physical classroom remains challenging. In other words, we cannot expect that simply making technology available to teachers and students will automatically translate to selfdirected learning (Y.-M. Huang, Huang, \& Wu, 2014; Y.-M. Huang, Huang, Liu, \& Tsai, 2013; Sieber, 2005). Therefore, as the instructor does in a conventional physical classroom, synchronous online classes must also be well managed in regard to motivating students to participate (Warden et al., 2013).

In order to keep abreast of student learning in a physical classroom, using in-class questions is an efficient instructional strategy. This strategy prevents one-sided communication and gives teachers an opportunity to fulfill student needs (Y.-M. Huang, Liu, Chen, \& Wen, 2014; Woolfolk, 2004). Moreover, learners exposed to in-class questions will concentrate their attention on the course unit and have a chance to immediately integrate newly learned knowledge into their existing base of knowledge (Chan, Tam, \& Li, 2011). In summary, in-class questions are considered to be an effective instructional strategy to remarkably promote class interaction between teachers and students (Williamson Sprague \& Dahl, 2009).

Moreover, some studies have found that discussing in-class questions in synchronous learning is beneficial. N. S. Chen, Wei, and Huang (2013) found that synchronous questions (such as quizzes, chat rooms, and oral communication) can provide timely and interactive feedback leading to both improved teaching and learning. Teachers can collect instructional information though synchronous questions that allow immediate changes in the pedagogy applied during instructional activities in order to advance real-time adaptivity to the level at which learners are understanding the material being taught at the time. Students receiving immediate feedback have opportunities for reflection and can therefore improve their performance. Also, Yang (2011) pointed out that a key element in successful learning through computer-mediated communication is to engage students in student-teacher interactions for online learning activities. Yang (2011) thus proposed a study for engaging students in online learning by developing in-class questions intended to enhance student-teacher interactions.

However, this instructional support does not always have a positive effect on students' online 
learning experiences (Y. M. Huang \& Chiu, 2014; Tsai, 2011; Ward, Peters, \& Shelley, 2010). Yang (2011) argued that students with a low cognitive level may resist synchronous in-class questions because they need more time to think and reflect on the questions. Thus, conducting in-class questions in synchronous learning may actually decrease their performance. Moreover, personality traits such as neuroticism can also affect students' learning experience with online inclass questions (C. M. Chen \& Lee, 2011). For example, highly trait-anxious students may struggle with answering questions in synchronous learning situations (Bullen, Strachan, Lindsay, Wilson, \& Robson, 1998). In other words, test anxiety and pressure are particularly intense when students are specifically required to answer an in-class question (Marsh, 1984). In particular, if individuals appear to lack the confidence that they can answer the questions correctly, they may adopt an irresponsible attitude towards such questions (Putwain, Sander, \& Larkin, 2013). Deci, Koestner, and Ryan (2001) attribute this phenomenon to students' ineradicable negative impression of assessments. Because teachers often deliver negative judgments based on students' test results, teachers asking in-class questions may precipitate students' fear of being punished if they answer incorrectly and consequently increase their resistance to this kind of in-class assessment.

In countries strongly influenced by Confucianism such as Taiwan, test anxiety and pressure are particularly intense when students are specifically required to answer in-class questions (J.-K. Chen \& Wei, 2011; Laurence Lwo \& Yuan, 2011). As noted by Jackson (2002), Chinese students are commonly anxious about being the center of attention. They may also lack the confidence needed to speak up or perhaps are afraid of losing face if they make a mistake when speaking in front of a class (Bond, 1992). A Confucian value, consideration of others, appears to be an important factor influencing Chinese students' anxiety about being subjected to in-class questions (Bond, 2010; Scollon, 1999; Teo, 2013).

Some researchers have therefore proposed the notion of replacing punishments for responding incorrectly to in-class questions with rewards for providing useful feedback (Liu et al., 2015; Murphy \& Rodriguez-Manzanares, 2009). A number of motivation theories in education predict that offering rewards can positively affect student performance (Dale H. Schunk, Pintrich, \& Meece, 2007). When they receive rewards, students will become motivated to do well again. For example, Hoffmann, Huff, Patterson, and Nietfeld (2009) provided tangible rewards for student test performance and investigated the improvement such rewards had on their motivation and learning achievement.

However, Deci et al. (2001) warned that providing tangible prizes as rewards for students' work sometimes may undermine their intrinsic motivation. Also, competing against classmates may evoke evaluative anxiety, especially when the academic standard in the class is high (Wehrens et al., 2010). As a result, Deci et al. (2001) suggested a need for further study to investigate the effect of different types of rewards for retaining learning motivation, such as providing students with more interesting learning activities and creating a positive atmosphere in synchronous learning.

In this work, we propose the idea of providing a virtual reward with a funny image in response to 
students' answers to in-class questions. This visual type of reward aims to arouse students' feelings of pleasure during an online synchronous learning activity. According to Fredrickson and Branigan's (2005) broaden-and-build theory, positive emotions broaden the scope of attention, cognition, and action, thus widening the array of perceptions, thoughts, and actions existing in the mind at the time. Previous studies (Park \& Lim, 2007; Um, Plass, Hayward, \& Homer, 2012) also have shown that providing multimedia learning content (e.g., images or videos) instead of using plain text can help maintain students' positive emotions, elicit more student attention, and produce an increase in students' sense of self-efficacy. Therefore, it is predicted that this type of reward will arouse students' positive emotions so as to focus their attention on course content, create a positive atmosphere, and increase their levels of learning achievement.

Based on the above discussion, a study is conducted to evaluate the effectiveness of in-class questions in synchronous learning where these questions are accompanied with positive visual stimuli that produce a positive effect. In this study, we attempt to answer the following questions:

(1) Does in-class questioning using positive visual stimuli have a greater effect in regard to eliciting affective states (such as positive emotions, levels of attention and relaxation) in students as compared to being asked questions that do not have any positive visual reward?

(2) Do students being asked in-class questions using positive visual stimuli experience a greater effect on their learning outcomes, as measured by higher test scores, than ones receiving questions without positive visual stimuli?

\section{Methodology}

\section{Participants}

The aim of this study was to examine the influence of funny image as positive visual stimuli. To ensure the effect of the funny image given as feedback, 42 participants ages 16-20 completed the learning activity in this study. The experimental group was made up of 21 participants given a funny image as feedback. The remaining 21 participants were the control group without the funny image as feedback. The topic of the learning activity was a general course in vocational high school, Basic Mechanical Design Course.

The construction of the in-class questions with funny images as rewards

The in-class questions with funny images as rewards were structured as multiple choice questions. The questions were presented via Microsoft PowerPoint (PPT). PPT provides interactive action buttons that allow different types of feedback based on the button that is clicked. As shown in Fig. 1, the questions and buttons displayed in the first slide were designed to determine the students' understanding of the material. The teacher selected a student to answer 
the question. When the student chose an answer, teacher clicked the action button. If the wrong answer was selected, the action button directed the presentation to a slide that showed that the choice was wrong. The teacher then explained why it was incorrect. The teacher then returned to the question and selected another student to attempt answering it again. If the correct answer was selected, the action button directed the presentation to a slide that confirmed the choice. The teacher explained why the answer was correct, and the student was rewarded with a funny image as a pleasure reward. The teacher could then advance to the next lecture unit. The design of rewarding only for the correct answer is based on achievement-based reward feedback. When a student provides a correct answer, presenting achievement-based rewards has been shown to increase student's intrinsic motivation and self-efficacy (D. H. Schunk, 1989). The feedback design was also used in a study by Moridis and Economides (2012).

Although students may need additional support from a teacher when they provide an incorrect answer to a question, achievement-based rewards can also help a student recover from a detrimental emotional state and low performance. When a student provides a correct answer, this is also a chance to present affective feedback (as a reward) so as to diminish the negative effect of previous wrong answers by increasing the student's intrinsic motivation and self-efficacy (McQuiggan, Mott \& Lester, 2008; Schunk, 1984, 1989).

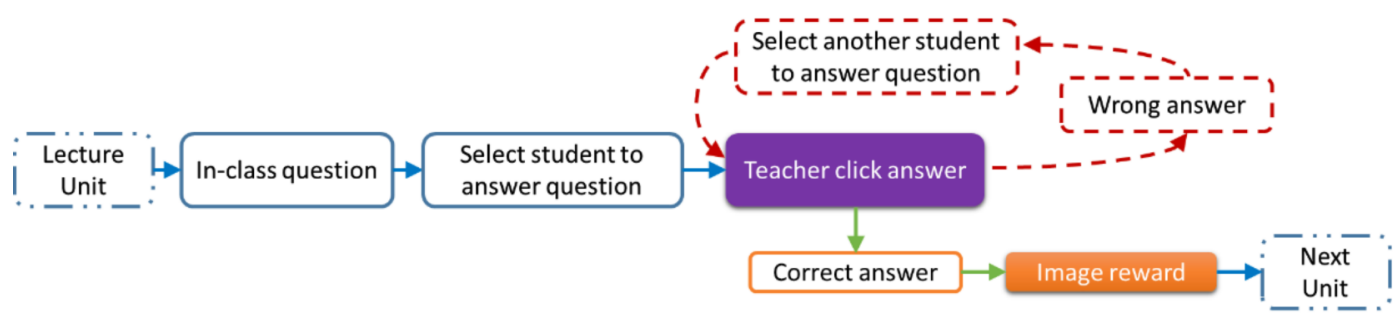

Figure 1. Flow chart for applying funny image rewards to in-class questions

\section{Instruments}

The study was implemented in an online learning environment, as shown in Figure 2. The participants were learning mechanical information through an online learning environment, Google Hangout (Teräs \& Teräs, 2012). Google Hangout is a communication platform used to conduct a synchronous learning environment in this study. The teacher could communicate to each participant in a chat box, or the students could talk to each other on Google Hangout. The main screen shared the learning material for every participant. Meanwhile, the participants accessed the learning environment by logging in. 


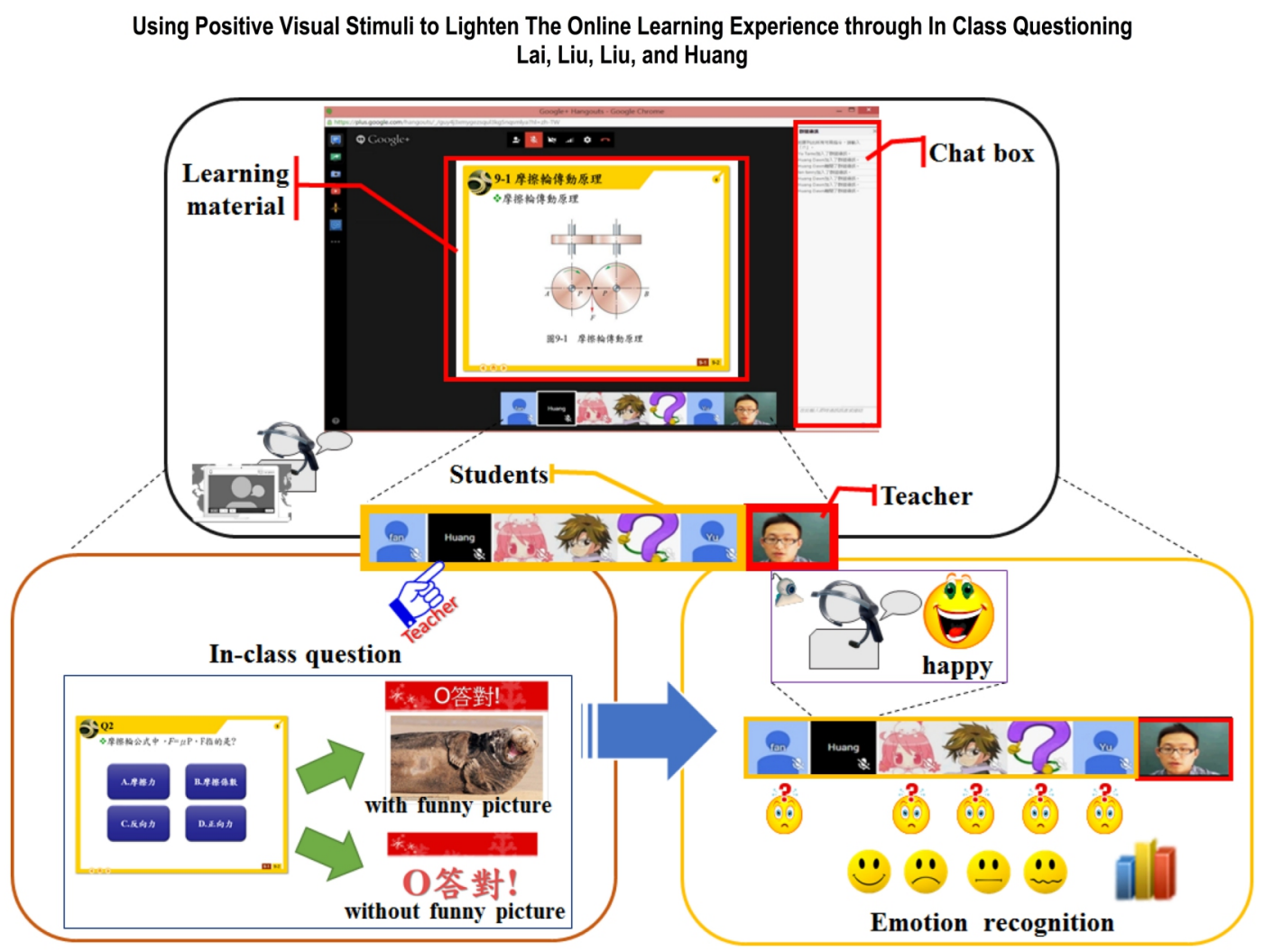

Figure 2. Experimental environment

\section{Emotion recognition with the facial expression software}

The emotion recognition images were taken with a webcam by using FaceReader facial expression software (see Figure 3). The method for indicating whether the emotional status of the subject is positive or negative is based on a valence value. 'Happy' is the only positive emotion, 'Sad', 'Angry', 'Scared' and 'Disgusted' are considered to be negative emotions. The valence is calculated as the intensity of 'Happy' minus the intensity of the negative emotion with the highest intensity. For instance, if the intensity of 'Happy' is 0.8 and the intensities of 'Sad', 'Angry', 'Scared' and 'Disgusted' are 0.1; 0.0; 0.05 and 0.05, respectively, then the valence is 0.7 . 


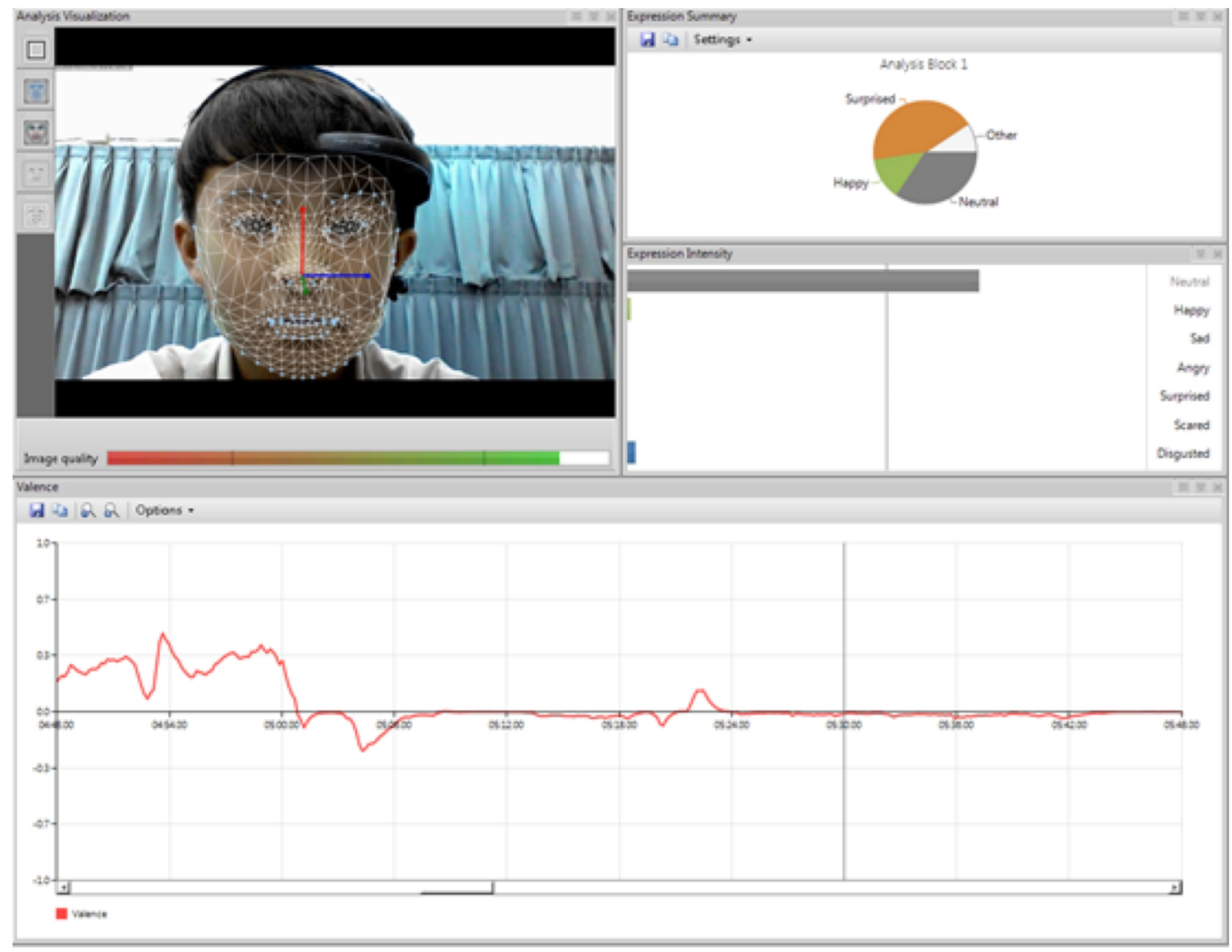

Figure 3. The interface of Facereader recognizing facial expressions

\section{Brainwave collection for attention and level of relaxation}

Crowley et al. (2010) proposed the use of a brainwave analysis method in the field. NeuroSky is a type of electroencephalograph (EEG) used to collect brainwaves. We used NeuroSky for the purpose of collecting the participants' brainwave data. Before the on-line synchronous learning occurred, each of the participants remained in a relaxed state and did nothing for one minute to obtain a base line for constructing the EEG valance. Through the EEG and the data analysis interface, the attention and level of relaxation were immediately calculated in a range from $o$ to 100. The attention and relaxation level records for all of the learning activities were collected.

\section{Procedure}

The study experiment included four parts (as shown in Figure 4): experimental description, pretest, web-based learning, and post-test. The first part, the experimental description, described the aim of the experiment and learning activity. However, the participants' facial characteristics and brain waves were recorded by webcam and NeuroSky. The consent was collected before the learning activity started. In the second part, the pre-test had ten items with a total score of 100 to ensure the prior knowledge of the participants. The NeuroSky mind wave and webcam were set up within 15 minutes after the pre-test. To ensure the correctness of the collected data, the participants' brain waves and facial characteristics were recorded for one minute to obtain the 
baseline. Third, the on-line synchronous learning activity included ten units for the purpose of learning common mechanical knowledge. The average time for learning each part was three minutes. Each of learning parts involved asking a question after it was completed. According to the answer, the teacher provided feedback. The feedback with or without a funny image was shown if the participant provided a correct answer depending on which group the participant had been assigned to. A total of 40 funny images was selected from the Internet. Eighty-nine undergraduates were used to evaluate the degree to which the images were funny. The top 10 images were selected for the feedback. In the fourth part, a post-test consisting of ten items was collected to evaluate learning effectiveness. The total time for the study was 100 minutes.

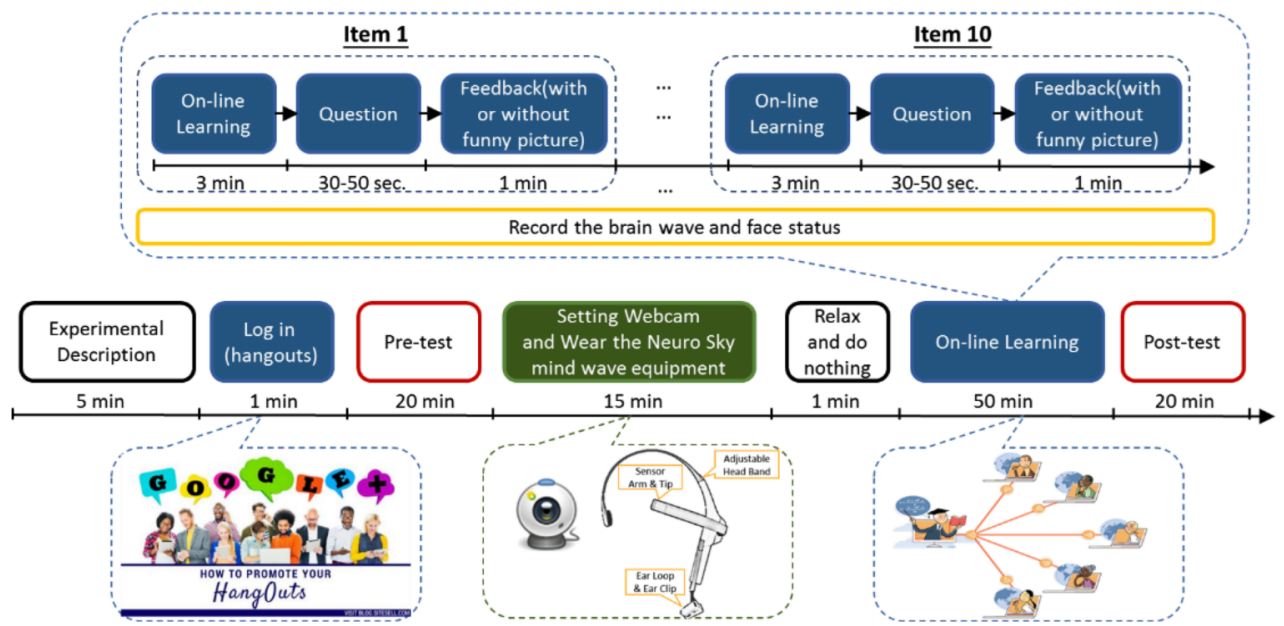

Figure 4. Study procedure

\section{Results and Discussion}

\section{Emotion recognition with facial expressions}

The valence indicated whether facial expressions were negative and to what degree. The valences of the participants were further analyzed by extracting those expressions occurring within five seconds after the questions were answered. Examination of the expressions was intended to indicate the influence of questions with or without an image on the participants' emotional state during the online synchronous learning. Figure 5 shows the average degree of negative valence in the case of the participants receiving an image or not receiving an image within five seconds of answering each question. The trend lines are plotted in Figure 5, along with the question series. The results illustrate that the participants having questions without rewards exhibited an upward linear trend. The $\mathrm{R}^{2}$ is 0.233 , indicating that more than $23 \%$ of the overall variance in the average degree of negative valence is explained by the linear trend of the question series. On the contrary,


indicating that more than $29 \%$ of the overall variance in the average degree of negative valence is 
explained by the linear trend of the question series. In other words, the delivery of a funny image for a correct answer consistently helped suppress negative emotions related to a learning activity.



Figure 5. The average degree of negative valence of the participants receiving images/not receiving images within five seconds of answering each question

Furthermore, the participants' level of attention and level of relaxation were analyzed by collecting their brainwave signals. Figure 6 reveals the level of attention of participants who either received the image reward or didn't receive it within five seconds of answering each question. The finding illustrates that the participants having questions without images exhibited a flat linear trend. The $\mathrm{R}^{2}$ was 0.001 , indicating that the overall variance in the level of attention cannot be explained by the linear trend in the question series. Meanwhile, the participants having questions with rewards show a downward linear trend. The $\mathrm{R}^{2}$ was 0.346 , indicating that more than $35 \%$ of the overall variance in the level of attention is explained by the linear trend in the question series. In other words, seeing a funny image as a reward for the correct answer consistently enhanced the participants' level of attention toward the learning activity. 


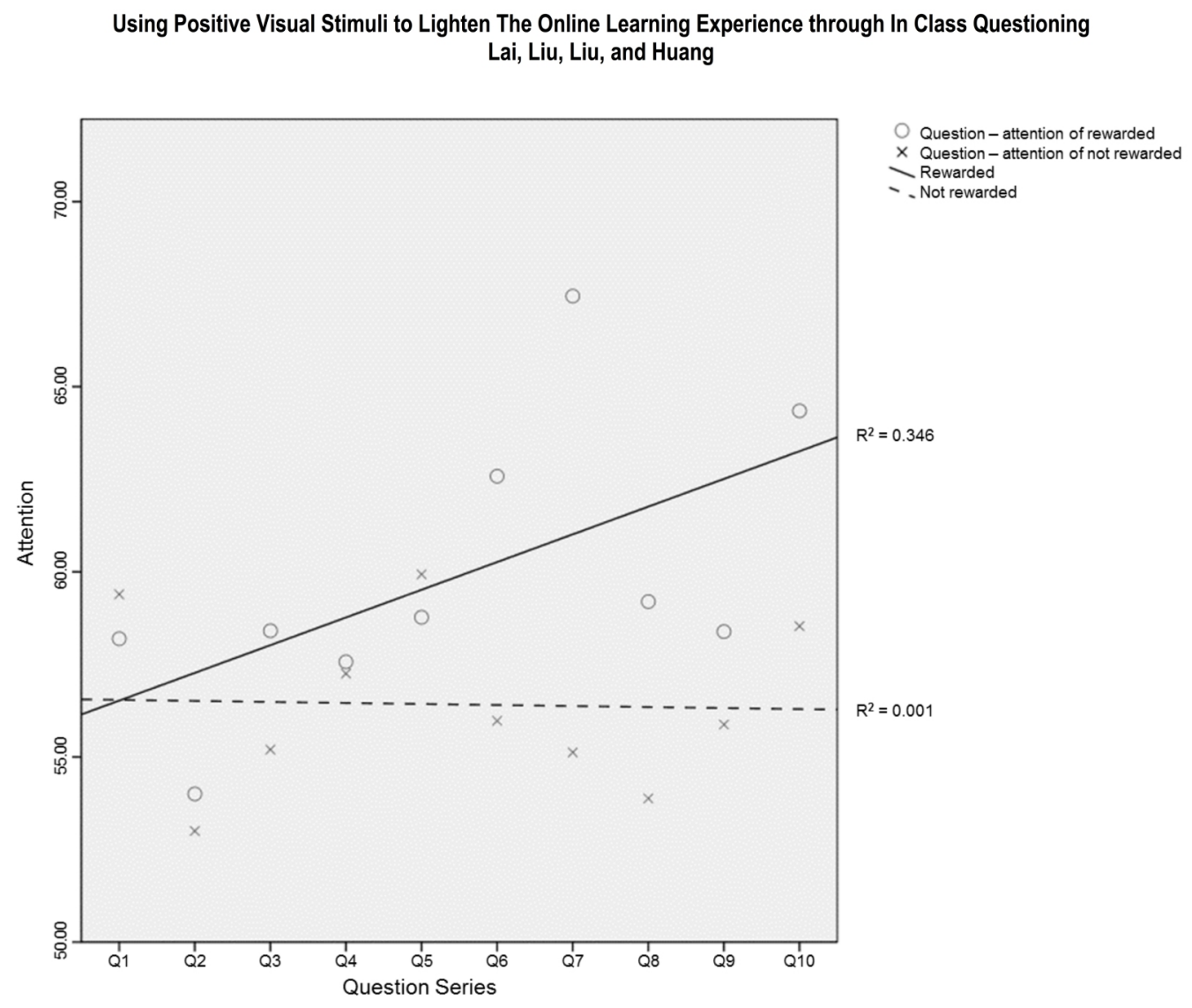

Figure 6. Level of attention of participants receiving images/not receiving images within five seconds of answering each question.

On the other hand, the participants' level of relaxation with or without a reward within five seconds of answering each question is shown in Figure 7. The findings indicate two opposite trends for participants' level of relaxation. The participants receiving no rewarded questions demonstrated a downward linear trend, where the $\mathrm{R}^{2}$ was 0.348 , indicating that more than $35 \%$ of the overall variance in the level of relaxation is explained by the linear trend in the question series. On the contrary, the participants receiving rewarded questions demonstrated a slight upward linear trend, where the $\mathrm{R}^{2}$ was 0.113 , indicating that more than $11 \%$ of the overall variance in the level of relaxation is explained by the linear trend in the question series. In other words, receiving rewards for answering questions soothed the participants' stressful emotions. 


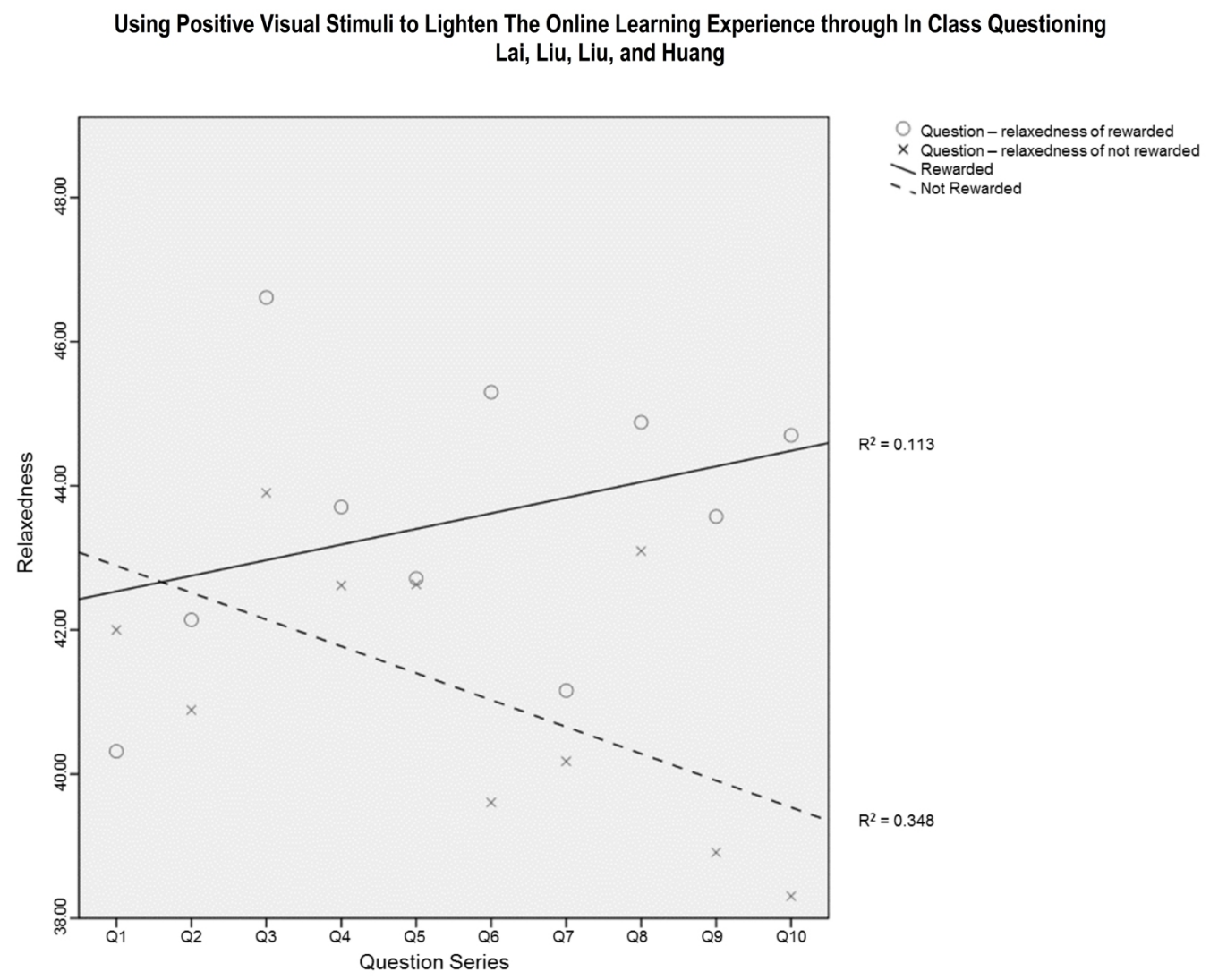

Figure 7. Level of relaxation of participants receiving images/not receiving images within five seconds of answering each question.

\section{Learning achievement}

Table 1 shows the participants' pre- and post-test scores. The pre-test mean scores for the participants' online learning with and without a funny image are 24.05 $(\mathrm{SD}=15.78)$ and 26.90 $(\mathrm{SD}=12.60)$, respectively. The post-test mean scores for the participants online learning with and without a funny picture are $85.47(\mathrm{SD}=10.11)$ and $80.95(\mathrm{SD}=12.71)$, respectively. Although the post-test scores of both groups show improvement over the pre-test score, the online learning occurring with a funny image exhibited a greater difference between the pre-test and post-test scores as compared with the participants' online learning occurring without a funny image. When the pre-test scores were applied as a covariate in the ANCOVA, it was indicated that the post-test scores were not significantly different between the groups, $\mathrm{F}(1,30)=1.495, p=.229$.

\section{Table 1}

Pre- and post-test mean scores, standard deviations, and analysis of covariance (ANCOVA) results for two groups

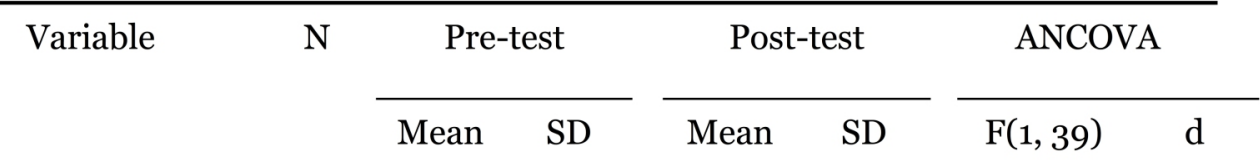




\begin{tabular}{|c|c|c|c|c|c|c|c|}
\hline \multicolumn{2}{|c|}{ Using Positive Visual } & \multicolumn{4}{|c|}{$\begin{array}{l}\text { ten The Online Learning Ex } \\
\text { Lai, Liu, Liu, and Huang }\end{array}$} & \multicolumn{2}{|c|}{ h In Class Questioning } \\
\hline $\begin{array}{l}\text { Without funny } \\
\text { picture }\end{array}$ & 21 & 24.05 & $15 \cdot 78$ & 80.95 & 12.71 & 1.495 & 0.37 \\
\hline With funny picture & 21 & 26.90 & 12.60 & 85.47 & 10.11 & & \\
\hline
\end{tabular}

In summary, although a detailed examination was conducted in this study, it was proven that receiving a funny image as positive visual stimuli for the correct answer was able to help arouse the students' positive affective states including positive emotions, level of attention, and level of relaxation. A similar study by Kennedy, Senses, and Ayan (2011) also showed that the use of multimedia content (such as a video clip) in class can give students pleasure so as to help increase their interest in the subject and to increase their level of critical thinking. Lepper and Greene (1978) further pointed out that a reward is particularly useful for increasing learners' motivation during a boring course. The funny image rewards in this paper are thus predicted to trigger learners' positive emotion during online classes.

More importantly, the rewarded questions were proven to slightly increase participants' exam scores. A number of motivational theories in education have predicted that offering rewards positively affects student performance (Schunk et al., 2007). In other words, when students receive rewards, they become motivated to do well again. The results echo Nittono, Fukushima, Yano, and Moriya's (2012) study indicating that people who are induced to experience positive feelings improve in regard to both task performance and attention.

\section{Pedagogical Implications}

As noted by Y. C. Kuo, A. E. Walker, B. R. Belland, K. E. E. Schroder, and Y. T. Kuo (2014), learner-instructor interaction has been found to be the strongest predictor of student satisfaction in synchronous online learning environments. This is because using synchronous learning tools can provide the benefit of real time knowledge sharing and immediate access to the instructor for questions or comments. Therefore, the instructor plays a major role in engaging students in synchronous online learning environments. In other words, the instructor should be responsive with regard to offering live lectures and initiating questions intended to enable discussion, particularly in Chinese culture, where students rely on teachers to fire questions at them (Levinsohn, 2007). However, previous research (C. M. Chen \& Lee, 2011; Coryell \& Clark, 2009; Yang, 2011) has suggested that students may experience negative emotions when they are assigned to answer questions in synchronous learning environments. For example, students at low cognitive levels may resist answering such questions, because they need more time to think and reflect on the questions (Yang, 2011). Also, test anxiety and pressure are particularly intense 
when students are specifically required to answer in-class questions (Marsh, 1984), especially in the case of Chinese students (J.-K. Chen \& Wei, 2011; Laurence Lwo \& Yuan, 2011). C. M. Chen and Lee (2011) further pointed out that negative emotions such as anxiety decrease learning performance in synchronous online learning environments. This phenomenon becomes worse in synchronous online learning environments because the instructor cannot make correct judgements about the emotional status of the students (C. M. Chen \& Lee, 2011).

Therefore, in order to engage students in synchronous online learning environments, the instructor should not only emphasize increasing performance, but also should take the approach of attracting positive affective states such as those experienced when employing funny images as pleasure rewards, as is proposed in the current study. One of the features that distinguishes visual rewards from other rewards is they not only entice students to increase performance, but also positively affect learners' affective states (e.g., sense of confidence) (Nittono et al., 2012). The other feature of a funny image reward is that it is given to groups rather than individuals. Sears and Pai (2012) demonstrated that this feature promotes a greater degree of knowledge sharing and group cohesiveness. In summary, this paper emphasizes the idea that the instructional design doesn't necessarily lead to high performance all the time. Nevertheless, instructional designers should consider students' emotions and levels of motivation when seeking to improve the probability of academic success by providing students with incremental joyful learning experiences during their course of study.

\section{Conclusions}

In the past, instructors employed in-class questions to motivate students to participate in a synchronous online learning environment. However, this strategy, which proved efficient in promoting class interaction between teachers and students in a conventional physical classroom (Williamson Sprague \& Dahl, 2009), may cause a negative effect on students' online learning experiences. As noted in Yamagata-Lynch's (2014) study, many participants commented that they feel anxious about learning in synchronous online learning environments (Yamagata-Lynch, 2014). One reason for this is that real-time interaction requires immediate responses, which may make students anxious (Ng, 2007). This phenomenon becomes worse for students with negative attitudes toward technologies and for those with high computer anxiety (Liaw \& Huang, 2013). The other reason is that students may experience negative emotions when they are assigned to answer questions in synchronous learning environments (Coryell \& Clark, 2009; Yang, 2011), and this is especially true of Chinese students (J.-K. Chen \& Wei, 2011; Laurence Lwo \& Yuan, 2011).

Therefore, this paper proposes that it is possible to improve synchronous learning experiences by rewarding answers to in-class questions with humorous visual images. The reason for providing such virtual rewards is to help develop a more positive attitude about the class. It is believed that students who experience pleasurable feelings will have higher motivation to learn, will pay more 
attention in class, and will get higher test scores (Kennedy et al., 2011; Lepper \& Greene, 1978; Nittono et al., 2012). Therefore, the effects of in-class questions with funny image rewards were examined in a synchronous online learning environment.

The results for the emotional states using FaceReader facial expression software revealed that the group answering questions with rewards demonstrated a higher degree of valence than those answering the questions without rewards. In other words, rewarded questions helped these participants experience positive emotions. Furthermore, the participants' levels of attention and relaxation were analyzed by collecting their brainwave signals. The findings illustrate that the participants receiving no rewarded questions exhibited a trend toward decreasing levels of attention. However, the participants whose questions were rewarded exhibited a trend toward increasing levels of attention. The findings for relaxation also showed that the participants receiving rewarded questions demonstrated a trend toward increasing levels of relaxation. In other words, questions with rewards were able to help arouse positive affective states in participants, such as positive emotions and higher levels of attention and relaxation. More importantly, the results showed that the group receiving funny images as pleasure rewards for answering correctly appeared to have slight increases in their exam scores. This result can be explained by the assumption that funny images as positive visual stimuli can promote positive learner-instructor interaction and create a better social presence in synchronous online learning environments (Y.-C. Kuo, A. E. Walker, B. R. Belland, K. E. Schroder, \& Y.-T. Kuo, 2014; Levine \& Pizarro, 2004; Zillmann, 1988). These findings suggest that the instructor should accompany inclass questions with simple rewards to induce positive affective states, even though this instructional strategy does not lead to higher student performance all the time.

\section{Acknowledgments}

This research is partially supported by the "Aim for the Top University Project" and "Center of Learning Technology for Chinese" of National Taiwan Normal University (NTNU), sponsored by the Ministry of Education, Taiwan, R.O.C. and the "International Research-Intensive Center of Excellence Program" of NTNU and Ministry of Science and Technology, Taiwan, R.O.C. under Grant no. MOST 104-2911-I-003-301, MOST 103-2511-S-006-007-MY3, and MOST 103-2511-So06-002-MY3.

\section{References}

Bond, M. H. (1992). Beyond the Chinese Face: Insights from Psychology Paperback. Oxford: Oxford University Press.

Bond, M. H. (2010). The Oxford Handbook of Chinese Psychology. Hong Kong: Oxford 
Using Positive Visual Stimuli to Lighten The Online Learning Experience through In Class Questioning

Lai, Liu, Liu, and Huang

University Press.

Bullen, P., Strachan, T., Lindsay, S., Wilson, D., \& Robson, S. (1998). Gene expression studies in post- implantation human embryos. BJOG: An International Journal of Obstetrics \& Gynaecology, 105(11), 1224-1224.

Chan, C. K. Y., Tam, V. W. L., \& Li, C. Y. V. (2011). A comparison of MCQ assessment delivery methods for student engagement and interaction used as an in-class formative assessment. International Journal of Electrical Engineering Education, 48(3), 323-337.

Chen, C. M., \& Lee, T. H. (2011). Emotion recognition and communication for reducing secondlanguage speaking anxiety in a web-based one-to-one synchronous learning environment. British Journal of Educational Technology, 42(3), 417-440.

Chen, J.-K., \& Wei, H.-S. (2011). Student victimization by teachers in Taiwan: Prevalence and associations.Child Abuse \& Neglect, 35(5), 382-39o. doi: http://dx.doi.org/10.1016/j.chiabu.2011.01.009

Chen, N. S., Wei, C. W., \& Huang, Y. C. (2013). The integration of print and digital content for providing learners with constructive feedback using smartphones. British Journal of Educational Technology, 44(5), 837-845.

Cole, M. (2009). Using Wiki technology to support student engagement: Lessons from the trenches. Computers \& Education, 52(1), 141-146. doi: 10.1016/j.compedu.2008.07.003

Coryell, J. E., \& Clark, M. C. (2009). One right way, intercultural participation, and language learning anxiety: A qualitative analysis of adult online heritage and nonheritage language learners. Foreign Language Annals, 42(3), 483-504.

Deci, E. L., Koestner, R., \& Ryan, R. M. (2001). Extrinsic rewards and intrinsic motivation in education: reconsidered once again. Review of Educational Research, 71(1), 1-27.

Fredrickson, B. L., \& Branigan, C. (2005). Positive emotions broaden the scope of attention and thought-action repertoires. Cognition \& Emotion, 19(3), 313-332. doi: 10.1080/02699930441000238

Hoffmann, K. F., Huff, J. D., Patterson, A. S., \& Nietfeld, J. L. (2009). Elementary teachers' use and perception of rewards in the classroom. Teaching and Teacher Education, 25(6), 843-849. doi: 10.1016/j.tate.2008.12.004

Huang, Y.-M., Huang, S.-H., \& Wu, T.-T. (2014). Embedding diagnostic mechanisms in a digital game for learning mathematics. Educational Technology Research and Development, 62(2), 187-207. 
Huang, Y.-M., Huang, Y.-M., Liu, C.-H., \& Tsai, C.-C. (2013). Applying social tagging to manage cognitive load in a Web 2.0 self-learning environment. Interactive Learning Environments, 21(3), 273-289.

Huang, Y.-M., Liu, M.-C., Chen, N.-S., \& Wen, D. (2014). Facilitating learners' web-based information problem-solving by query expansion-based concept mapping. Australasian Journal of Educational Technology, 3o(5).

Huang, Y. M., \& Chiu, P. S. (2014). The effectiveness of a meaningful learning- based evaluation model for context- aware mobile learning. British Journal of Educational Technology.

Jackson, J. (2002). Reticence in second language case discussions: anxiety and aspirations. System, 3o(1), 65-84. doi: http://dx.doi.org/10.1016/So346-251X(01)0oo51-3

Kennedy, N. F., Senses, N., \& Ayan, P. (2011). Grasping the social through movies. Teaching in Higher Education, 16(1), 1-14. doi: 10.1080/13562517.2010.507305

Kuo, Y.-C., Walker, A. E., Belland, B. R., Schroder, K. E., \& Kuo, Y.-T. (2014). A case study of integrating Interwise: Interaction, internet self-efficacy, and satisfaction in synchronous online learning environments. The International Review of Research in Open and Distance Learning, 15(1).

Kuo, Y. C., Walker, A. E., Belland, B. R., Schroder, K. E. E., \& Kuo, Y. T. (2014). A case study of integrating interwise: Interaction, Internet self-efficacy, and satisfaction in synchronous online learning environments. International Review of Research in Open and Distance Learning, 15(1), 21.

Laurence Lwo, L.-S., \& Yuan, Y.-S. (2011). Teachers' perceptions and concerns on the banning of corporal punishment and its alternative disciplines. Education and Urban Society, 43(2), 137-164. doi: 10.1177/0013124510380232

Lepper, M. R., \& Greene, D. (1978). The Hidden Costs of Reward: New Perspectives on the Psychology of Human Motivation. New York: Lawrence Erlbaum.

Levine, L. J., \& Pizarro, D. A. (2004). Emotion and memory research: A grumpy overview. Social Cognition, 22(5), 530-554. doi: 10.1521/soco.22.5.530.50767

Levinsohn, K. R. (2007). Cultural differences and learning styles of Chinese and European trades students. Institute for Learning Styles Research Journal, 1, 12-22.

Liaw, S. S., \& Huang, H. M. (2013). Perceived satisfaction, perceived usefulness and interactive learning environments as predictors to self-regulation in e-learning environments. Computers \& Education, 6o(1), 14-24. doi: 10.1016/j.compedu.2012.07.015 
Liu, C.-J., Huang, C.-F., Liu, M.-C., Chien, Y.-C., Lai, C.-H., \& Huang, Y.-M. (2015). Does gender influence emotions resulting from positive applause feedback in self-assessment testing? Evidence from neuroscience. Journal of Educational Technology \& Society, 18(1), 337350.

Marsh, R. (1984). A comparison of take-home versus in-class exams. The Journal of Educational Research, 78(2), 111-113.

Moridis, C. N., \& Economides, A. A. (2012). Applause as an achievement-based reward during a computerised self-assessment test. British Journal of Educational Technology, 43(3), 489-504. doi: 10.1111/j.1467-8535.2011.01221.x

Murphy, E., \& Rodriguez-Manzanares, M. A. (2009). Sage without a stage: Expanding the object of teaching in a web-based, high-school classroom. The International Review of Research in Open and Distance Learning, $10(3)$.

Ng, K. C. (2007). Replacing face-to-face tutorials by synchronous online technologies: Challenges and pedagogical implications. International Review of Research in Open and Distance Learning, 8(1), 1-8.

Nittono, H., Fukushima, M., Yano, A., \& Moriya, H. (2012). The power of Kawaii: Viewing cute images promotes a careful behavior and narrows attentional focus. Plos One, 7(9), 7. doi: 10.1371/journal.pone.0046362

Park, S., \& Lim, J. (2007). Promoting positive emotion in multimedia learning using visual illustrations. Journal of Educational Multimedia and Hypermedia, 16(2), 141-162.

Putwain, D., Sander, P., \& Larkin, D. (2013). Academic self-efficacy in study-related skills and behaviours: Relations with learning-related emotions and academic success. British Journal of Educational Psychology, 83(4), 633-650. doi: 10.1111/j.20448279.2012.02084.x

Schunk, D. H. (1989). Self-efficacy and achievement behaviors. Educational Psychology Review, 1(3), 173-208. doi: 10.1007/bfo1320134

Schunk, D. H., Pintrich, P. R., \& Meece, J. R. (2007). Motivation in Education: Theory, Research, and Applications (3rd Ed.). NJ: Pearson.

Scollon, S. (1999). Not to waste words or students: confucian and socratic discourse in the tertiary classroom. In E. Hinkel (Ed.), Culture in Second Language Teaching and Learning (pp. 13-27). Cambridge: Cambridge University Press.

Sears, D. A., \& Pai, H. H. (2012). Effects of cooperative versus individual study on learning and motivation after reward-removal. Journal of Experimental Education, 8o(3), 246-262. 
Using Positive Visual Stimuli to Lighten The Online Learning Experience through In Class Questioning

Lai, Liu, Liu, and Huang

doi: 10.1080/00220973.2011.602372

Sieber, J. E. (2005). Misconceptions and realities about teaching online. Science and Engineering Ethics, 11(3), 329-340. doi: 10.1007/s11948-005-0002-7

Teo, P. (2013). 'Stretch your answers': Opening the dialogic space in teaching and learning. Learning, Culture and Social Interaction, 2(2), 91-101. doi: http://dx.doi.org/10.1016/j.lcsi.2013.02.002

Teräs, H., \& Teräs, M. (2012). Using Google tools for authentic learning and progressive inquiry in 21st century faculty development. Paper presented at the Society for Information Technology \& Teacher Education International Conference.

Tsai, C.-W. (2011). Achieving effective learning effects in the blended course: A combined approach of online self-regulated learning and collaborative learning with initiation. Cyberpsychology, Behavior, and Social Networking, 14(9), 505-510.

Um, E. R., Plass, J. L., Hayward, E. O., \& Homer, B. D. (2012). Emotional design in multimedia learning. Journal of Educational Psychology, 104(2), 485-498. doi: 10.1037/aoo26609

Ward, M. E., Peters, G., \& Shelley, K. (2010). Student and faculty perceptions of the quality of online learning experiences. The International Review of Research in Open and Distance Learning, 11(3), 57-77.

Warden, C. A., Stanworth, J. O., Ren, J. B., \& Warden, A. R. (2013). Synchronous learning best practices: An action research study. Computers \& Education, 63, 197-207. doi: 10.1016/j.compedu.2012.11.010

Wehrens, M., Buunk, A. P., Lubbers, M. J., Dijkstra, P., Kuyper, H., \& van der Werf, G. P. C. (2010). The relationship between affective response to social comparison and academic performance in high school. Contemporary Educational Psychology, 35(3), 203-214. doi: 10.1016/j.cedpsych.2010.01.001

Williamson Sprague, E., \& Dahl, D. W. (2009). Learning to click: An evaluation of the personal response system clicker technology in introductory marketing courses. Journal of Marketing Education, 32(1), 93-103. doi: 10.1177/0273475309344806

Woolfolk, A. (2004). Educational psychology (9th Ed.). Boston, MA: Allyn \& Bacon.

Yamagata-Lynch, L. C. (2014). Blending online asynchronous and synchronous learning. International Review of Research in Open and Distance Learning, 15(2), 189-212.

Yang, Y.-F. (2011). Engaging students in an online situated language learning environment. Computer Assisted Language Learning, 24(2), 181-198. 
Using Positive Visual Stimuli to Lighten The Online Learning Experience through In Class Questioning

Lai, Liu, Liu, and Huang

Zillmann, D. (1988). Mood management: Using entertainment to full advantage. Communication, social cognition, and affect, 147-171.

Athabasca

University

(c) (†) 